\title{
Do sublime: a estética crítica e a Tragédia pensada por Friedrich Schiller
}

\section{From the sublime: critical aesthetics and Tragedy by Friedrich Schiller}

\author{
Bárbara Ferrario Lulli \\ Graduação em andamento em Filosofia (2013), Universidade Estadual Paulista Júlio de Mesquita Filho \\ - UNESP. Faculdade de Filosofia e Ciências - FFC. Campus Marília - SP.
}

\begin{abstract}
Resumo: Este artigo tem como objetivo apresentar a compreensão do conceito de sublime no texto Do sublime - Para uma exposição ulterior de algumas ideias kantianas, publicado por Friedrich Schiller, em 1793, no periódico Neue Thalia. Neste ensaio, o autor se insere propriamente na discussão acerca do sublime e sua fruição estética, adotando como seu principal respaldo a filosofia de Kant. Diante disso, pretendemos analisar as influências kantianas sobre o pensamento schilleriano e também sua autonomia, dado que o autor contou não somente com seus estudos teóricos a respeito do assunto, mas também com sua experiência de poeta e dramaturgo. Assim, mostraremos por meio de uma fiel leitura de Do sublime a problemática deste conceito e como ele se encaixa na noção de Tragédia pensada por Schiller.
\end{abstract}

Palavras-chave: Friedrich Schiller; sublime; Tragédia.

\begin{abstract}
This article aims to present an understanding of the concept of sublime in the text of the sublime - For a later exposition of some Kantian ideas, published by Friedrich Schiller, in 1793, in the periodical Neue Thalia. In this essay the author properly inserts himself in the discussion about the sublime and its aesthetic fruition, adopting as its main support the philosophy of Kant. In view of this, we intend to analyze the Kantian influences on schillerian thought and its autonomy, since the author counted not only with his theoretical studies on the subject, but also with his experience as a poet and playwright. Thus, we will show by means of a faithful reading of the sublime Do, the problematic of this concept and how it fits in the notion of Tragedy thought by Schiller.
\end{abstract}

Keywords: Friedrich Schiller; sublime; Tragedy. 


\section{Introdução}

As produções teóricas de Friedrich Schiller (1759-1805) acerca do sublime foram iniciadas em 1790, momento em que passou a escrever para o periódico Neue Thalia, no qual abordou não somente o tema do sublime, mas também da tragédia, com o intuito de explicar em que consistem as experiências estéticas. Neste campo, suas investigações a respeito de tal conceito se iniciaram com Do sublime (Vom Erhabenen), escrito em 1793, o qual tem como subtítulo Para uma exposição ulterior de algumas ideias kantianas (Zur Weitern Ausführungeiniger kantischen Ideen). Assim, como o próprio subtítulo sugere, suas pesquisas foram vinculadas às produções teóricas de Kant, característica que colocou Schiller em um direto diálogo com a filosofia crítica, em especial com a Crítica da faculdade do Juízo (1790) com o propósito de, como afirma-nos Vladimir Vieira, "[...] desenvolver suas investigações empregando ferramentas críticas tomadas de empréstimo ao sistema transcendental [...]" (VIEIRA, 2011, p. 9).

O periódico Neue Thalia tinha como objetivo a publicação de estudos e pesquisas na área da estética, do qual Schiller associou-se no período compreendido entre 1784 a 1795. Neste momento, elaborou textos de grande notoriedade como Acerca da razão por que nos entretêm assuntos trágicos e Sobre a arte trágica, ambos de 1792, Sobre graça e dignidade de 1793, dentre outros, cujo alguns fundamentos foram adotados da filosofia kantiana. Além de Do sublime, o conceito de sublime é abordado por Schiller em outro texto, chamado Sobre o sublime [Über das Erhabene]. Em ambos, o sublime é retratado como um sentimento antagônico que se caracteriza por intercalar sensações de desprazer e prazer, como modo de apresentar um "princípio autônomo" (SCHILLER, 2011, p. 60) do homem responsável pelo elemento que o fundamenta enquanto tal, a saber, a liberdade, expressa em sua vontade.

Embora não se diferencie em ambos os textos o objeto análise, a abordagem que Schiller adota parece priorizar nos diferentes textos aspectos diversos do sublime. Se em Do sublime pode-se dizer que há o privilégio de uma análise descritiva do sublime, ressaltando a definição de sua experiência - que, por sua vez, fundamenta-se sobre a filosofia crítica de Kant, em especial da Crítica da faculdade do Juízo (1790) -, em Sobre o sublime o filósofo faz preferencialmente a abordagem carregada por uma perspectiva antropológica, dentro da qual se preocupa em responder questões sobre o tema da formação do homem, bem como sobre sua realização plena num mundo fragmentado do qual faz parte, desenvolvendo nesse contexto o papel do sublime na cultura.

Ainda que algumas destas mesmas questões sejam ressaltadas também em Do sublime, neste último, o autor adotou uma abordagem que, como afirma Vladimir Vieira, "documenta de modo inequívoco a diligência de Schiller em operar suas reflexões sobre estética, à época da Neue Thalia, a partir do quadro conceitual do sistema transcendental" (VIEIRA, 2011, p. 13), característica esta que o fez fundamentar o sublime sobre as bases da Analítica do sublime. Distinguiu, assim, os sublimes matemático e dinâmico, os quais chamou de teórico e prático e, com isso, adotou aos seus estudos estéticos, de acordo com Anatol Rosenfeld, "um problema que não é aristotélico e sim tipicamente kantiano: a tentativa de determinar a relação entre as esferas moral, estética e a do mero prazer sensível [...]". (ROSENFELD, 1991, p. 9).

No entanto, sua empreitada não se resumiu à descrição dos sublimes kantianos. Schiller contribuiu com o assunto incorporando aos estudos um desdobramento do sublime prático em "sublime contemplativo do poder" e "sublime patético". Esta característica, dentre outras, nos permite notar que mesmo sob as influências de Kant, Schiller - tendo em vista sua relação com a arte - se preocupou em pensar os fenômenos estéticos de modo mais vasto e abrangente. Este traço eclodiu em Sobre o sublime, publicado em 1801, incluído em Escritos menores em prosa, onde o filósofo 
desenvolveu uma abordagem de cunho antropológico e se concentrou não em uma formulação conceitual kantiana a respeito do sublime, mas sim na formulação de uma filosofia estética capaz de entender e explicar o que é o homem e, além disso, refletir sobre como a arte pode desempenhar um importante papel na problemática que o ocupa, isto é, no impasse entre a vontade, que o caracteriza como tal, e suas necessidades que o ameaçam e, sobretudo, podem anular o conceito de ser humano (SCHILLER, 2011, p. 56).

A publicação de Sobre o sublime indica uma possível reformulação de Do sublime; como aponta Pedro Süssekind, haveria ali "o privilégio dado pelo autor ao desenvolvimento de uma teoria própria, não mais vinculada à terminologia e aos argumentos de Kant" (SÜSSEKIND, 2011, p. 95). Ademais, outro ponto cardeal nesta sua perspectiva diferenciada é a ideia de cultura, meio pelo qual o homem pode se equiparar à natureza, tornando-se independente dela. Como afirma o próprio o autor, "A cultura deve pôr o homem em liberdade e auxiliá-lo a preencher por completo o seu conceito. Portanto, ela deve torná-lo capaz de afirmar sua vontade, pois o homem é o ser que quer". (SCHILLER, 2011, p. 56).

Caracterizando, então, o ser humano como aquele que age pela vontade, Schiller atribui à cultura a possibilidade de fazê-lo exercer sua liberdade no mundo sem deixar que a irremediável morte o assole, uma vez que é por meio da cultura que o homem pode se deleitar com a grandiosa força que a natureza é capaz de exercer sobre ele, deixando de temê-la para afirmar, assim, a sua liberdade através do deleite. Tal deleite, segundo Schiller, é reforçado e intensificado pela arte, propriamente pela arte trágica, que tem o sublime patético como seu principal sentimento; de acordo com Ritchie Robertson, " [...] porque o sublime nos obriga a ir além da harmonia da beleza e exercer um tipo de violência em nosso senso estético" ${ }^{11}$, fortificando-nos.

Dada esta flexibilidade da noção de sublime encontrada na estética filosófica schilleriana, temos como objetivo neste artigo apresentar o conceito de sublime em Do sublime, de modo a ressaltar seus aspectos e a possível relação de Schiller com Kant.

\section{A "estética crítica"2 de Schiller}

Pode-se dizer que Schiller encontrou em Kant a possibilidade de fundamentar suas reflexões filosóficas acerca da arte, em especial da arte trágica, utilizando-se do aparato crítico como respaldo para seu conhecimento prático enquanto dramaturgo e poeta. Característica que evidencia a preocupação de Schiller em compreender o que circunda as atividades estéticas. Assim como nos confirma Anatol Rosenfeld, "No centro de suas indagações de esteticista encontram-se desde logo, o problema de determinar o lugar e a função exatos da arte - e em especial da arte teatral - dentro do contexto da sociedade e dentro das virtualidades humanas". (ROSENFELD, 1991, p. 7).

Essa discussão ocupa em grande parte os estudiosos da estética schilleriana que sugerem razões pela qual Schiller se envolveu com a filosofia de Kant. Um dos estudiosos que corroboram com esta pesquisa é Vladimir Vieira, que sugere que o grande interesse de Schiller em fundamentar a fruição estética e suas sensações pode ser oriundo de seu trabalho como poeta e dramaturgo. Ainda segundo o pesquisador, após a publicação da peça Don Carlos (1790) e o intenso compromisso com as suas investigações e preleções para a Universidade de Jena, na qual lecionou para o Departamento de História, Schiller sofrera um momento de "crise poética"

1 "[...] because the sublime requires us to move beyond the harmony of beauty and even exercise a kind of violence on our aesthetic sense" (ROBERTSON, 2013, p. 209. Tradução nossa).

2 VIEIRA, V. Os dois sublimes de Schiller. In: Friedrich Schiller. Do sublime ao trágico. 2001. p. 11. 
(VIEIRA, 2011, p. 8), durante a qual pode ter buscado por meio da filosofia kantiana fundamentar conceitualmente suas atividades artísticas.

Ante tais noções, Vladimir Vieira afirma que os textos publicados em Neue Thalia entre os anos de 1792 e 1793 "[...] caracterizaram-se pelo acento notadamente crítico" (IBID., p. 10), característica que confirma o entusiasmo de Schiller por Kant e a intenção de tomar seu sistema como arcabouço teórico para a construção de sua crítica. Desse modo, Schiller voltou sua atenção à busca de um princípio que consolidasse a cultura moderna, que segundo ele sofria por conta da cisão instaurada pelo Iluminismo entre razão e sensibilidade.

A tragédia surge, então, como a experiência que revela as emoções em seu desenvolver-se, desencadeando as paixões e mostrando que "[...] o prazer no afeto está em relação justamente aposta ao conteúdo", (SCHILLER, 1991, p. 83). Isto é, para Schiller, a tragédia deve elevar seu espectador acima do antagonismo entre suas faculdades, e emancipá-lo do domínio da "[...] dolorosa intensidade da compaixão, [...]" (IBID., p. 84) ou do domínio onde se é "[...] mantido em seus limites pelas leis do decoro" (IBID). Schiller faz sob sua análise da tragédia um elogio ao prazer como atividade sem finalidade, e vê na arte a possibilidade de apreciá-lo como "[...] fim supremo" (IBID., p. 90), suscitando a compaixão como meio de mostrar ao espectador suas potencialidades, deleitando-o com o prazer de reconhecer-se enquanto ser humano em sua plena virtualidade.

Todavia, essa noção schilleriana de tragédia não é derivada da Poética de Aristóteles como sua tradição. De acordo com pesquisadores como Anatol Rosenfeld, isso se deve ao fato de Schiller ter lido a Poética somente em 1797, depois de já ter elaborado boa parte de seus escritos teóricos e inclusive depois de ter publicado sua célebre obra, a Educação estética do homem, de 1795. Com isso, Schiller manteve-se de certa forma independente da tradição de filósofos e dramaturgos que buscaram fundamentar o teatro sobre as bases da Poética aristotélica, como foi o caso de Lessing. Por conta disso, Schiller expandiu suas análises acerca da tragédia para os domínios da filosofia - em especial a kantiana - fazendo com que seus estudos fossem além "[...] do exame exclusivo da tragédia, abordando também o problema do próprio trágico, [...], como forma estética peculiar em que esta situação humana encontra a sua expressão máxima mais poderosa" (ROSENFELD, 1991, p. 9).

Embora se possa admitir que Kant foi fundamental para Schiller, não se pode, ao contrário disso, afirmar que a filosofia schilleriana permaneceu submissa ao sistema crítico. A autenticidade de Schiller se apresenta através de seu compromisso com a estética e a cultura, pois, como afirma de Ricardo Barbosa, "Schiller estava convencido de que com a Crítica da faculdade do juízo, Kant abrira as portas para a estética, [...]." (BARBOSA, 2004, p. 14), pois a esta:

“[...] não se segue nenhuma doutrina, pois seria rigorosamente impossível um princípio objetivo para o belo e o gosto. No entanto, é precisamente o fundamento de determinação desse princípio que Schiller julgara ter encontrado - e isso com os meios da própria filosofia de Kant" (IBID., p. 15).

Ao buscar a filosofia crítica, Schiller pretendia fundamentar sobre os seus seguros alicerces o domínio artístico na tentativa de melhor compreender em que consiste o gosto e como se dá sua fruição. A importância de se objetivar o gosto surge, para Schiller, como meio fundamental para atingir seu objetivo de fazer com que a arte seja propriamente o meio libertador do homem na modernidade. Sendo assim, podemos notar que apesar do importante legado kantiano, Schiller constituiu sua própria filosofia com o objetivo de consolidar uma educação estética capaz de harmonizar as leis da razão com os sentidos. Essa característica confere autenticidade à filosofia schilleriana, posto que por trás de todo o interesse pela filosofia crítica havia seu compromisso estético em resgatar através da arte a então subestimada sensibilidade 
humana, libertando-a das condições impostas pela modernidade, trazendo, então, o almejado equilíbrio à humanidade.

Diante dos argumentos que embasam essa discussão, no próximo tópico nosso compromisso figura-se em apresentar alguns dos traços kantianos na obra Do sublime, de modo a pontuar alguns dos fundamentos sobre os quais se configura a filosofia de Schiller. Como afirma Pedro Süssekind a respeito desta mesma obra, o objetivo de Do sublime é "[...] apropriar-se da argumentação kantiana para, a partir dela, refletir sobre novas possibilidades da experiência estética [...]" (SÜSSEKIND, 2011, p. 87).

\section{Leitura de do sublime}

Do sublime inicia-se de modo bastante objetivo ao estabelecer seu objeto de análise. Schiller apresenta de antemão sua definição: "Sublime denominamos um objeto frente a cuja representação nossa natureza sensível sente suas limitações, enquanto nossa natureza racional sente sua superioridade, sua liberdade de limitações; [...]" (IBID., p. 21). Assim, segue a definição a característica básica do sublime em seus dois momentos antagônicos: primeiramente, nos sentimos frágeis enquanto seres sensíveis e passíveis a sofrer com os perigos que o mundo externo a nós pode nos oferecer. Posteriormente, percebemos que enquanto seres racionais não somos tão vulneráveis e conseguimos ir além do que nos é oferecido sensivelmente. Desse modo, esta definição segue, como afirma Vladimir Vieira, "Como na terceira crítica, a descrição fenomenológica tradicionalmente reconhecida como sinal de manifestação dessa categoria - um par de sentimentos, o prazer que se segue ao desprazer - é explicada em termos de um conflito entre nossas capacidades sensíveis e suprassensíveis". (IBID., p. 13).

Schiller, então, segue a descrição afirmando que o sublime é "[...], portanto, um objeto contra o qual levamos a pior fisicamente, mas sobre o qual, nos elevamos moralmente, i.e., por meio de ideias." (IBID., p. 21). De acordo com a citação, Schiller parece concordar com Kant ao afirmar que sublime não é ele mesmo o objeto em questão, dado que, de acordo com o último, "[...] o verdadeiro sublime não pode estar contido em nenhuma forma sensível [...]" (KANT, 1995, p. 91), pois, ele "[...] concerne somente a ideias da razão [...]" (IBID). Dessa forma, em ambos os casos, o sublime é uma sensação cujo objeto de representação apraz à razão despertando, assim, a sensação de sua superioridade frente às representações da natureza.

Neste sentido, para ambos os filósofos o sublime concerne às "ideias da razão" (IBID), visto que as representações sensíveis não são elas mesmas sublimes, mas são meios pelos quais ele se apresenta e, por isso, são capazes de serem "[...] evocadas ao ânimo precisamente por essa inadequação, que se deixa apresentar sensivelmente." (IBID). Baseado nesta descrição, podemos notar a consonância entre as noções de Schiller e Kant a respeito do sublime, dado que em ambos esta sensação não contém referencial empírico, mas somente suprassensível. Característica que elucida que o sublime schilleriano busca, assim como em Kant, ultrapassar o âmbito do puro sensível, visto que nele o homem sente clamarem suas necessidades, e sob a intenção de desgarrá-lo de suas limitações o sublime se coloca como o deleite da liberdade.

Deste modo, o ensaio segue a noção kantiana quando se refere ao mundo sensível como aquele que nos coloca em dependência, enquanto a razão nos traz a emancipação, isto é, a independência. Esta noção está na base da compreensão do que é o sublime em sua dupla manifestação: ora temorosa, ora prazerosa. Sob a representação do temor, o sublime nos faz reconhecer na qualidade de seres sensíveis e, por isso, dependentes de tudo aquilo que compartilha conosco esta mesma propriedade. A qual, ao ser colocada em perigo, nos faz sentir a ameaça à nossa existência ou às condições pelas quais atingimos conhecimentos. 
Embora tal sensação possa nos causar desprazer em um primeiro momento, posteriormente podemos nos sentir livres, dado que percebemos que além de seres sensíveis somos racionais, e esta última propriedade não se limita às imposições que a natureza pode nos impor: ela nos faz sentir independentes. Por conta disso, somos tomados por uma sensação de pleno regozijo e deleite - e estas características estão na base do que se pode entender por sublime. Assim, o sublime é explicado por Schiller como aquele que:

[...] nos faz, em primeiro lugar, sentir nossa dependência enquanto seres naturais ao tornar para nós conhecida, em segundo lugar, a independência que mantemos, enquanto seres racionais, com relação à natureza tanto em nós quanto fora de nós. (SCHILLER, 2011, p. 22).

Embora Schiller adote certos fundamentos emprestados de Kant, podemos notar sua flexibilidade ao usar os termos dependência e independência. Sem se deter propriamente à definição de tais noções, Schiller parte destas para explicar a relação do homem com a natureza e o modo como o sublime é desencadeado. Pode-se notar que a natureza desenvolve também um papel duplo em sua concepção: ela está "[...] tanto $\mathrm{em}$ nós quanto fora de nós". (IBID). Contudo, por haver um mesmo fundamento entre o que há fora e em nós, não a percebemos como algo distinto $e m$ nós. Essa relação só pode ser percebida, segundo Schiller, no momento em a natureza externa a nós se manifesta "[...] em luta com aquilo que é para nós carência [...]" (IBID), isto é, essa relação só se torna consciente na medida em que a natureza que conhecemos externamente entra em conflito com o que nos há internamente, pois, "enquanto a natureza fora de nós permanece conforme às condições sob as quais algo se torna possível em nós, não podemos sentir nossa dependência" (IBID).

Fora de nós, a natureza pode atuar como aquela que nos fornece condições de sobrevivência e, quando em conflito, pode nos ameaçar. Neste momento, segundo Schiller, somos impelidos a agir através de dois principais impulsos que em favor da nossa existência tentam não nos deixar sucumbir. Esses impulsos são: o de representação ou de conhecimento, responsável por "[...] alterar nosso estado, de exprimir nossa existência, de ser atuantes, e tudo isso equivale a adquirir representações [...]" (IBID), isto é, o impulso responsável por manifestar tudo o que representamos enquanto seres existentes. O segundo é o impulso de autoconservação, o qual é responsável por "[...] conservar nosso estado, de levar adiante nossa existência [...]" (IBID).

Assim, esses impulsos nos colocam em dependência com a natureza, pois são responsáveis por nos acautelar em situações onde ela pode vir a nos comprometer. Neste caso, quando ela se torna em alguma hipótese uma objeção, percebemo-la tanto como algo fora de nós, quanto em nós e, somente assim, em desarmonia com este mesmo princípio ativo que atua em ambos os domínios é que podemos constatá-la conscientemente. Essa consciência vem à tona na medida em que, diante de uma contradição, nossos impulsos são impelidos a atuar nos mostrando que somos dependentes da natureza de duas formas: "[...] quando a natureza deixa faltarem as condições nas quais atingimos conhecimentos" (IBID., p. 23), com o impulso de representação ou conhecimento no âmbito teórico; ou "[...] quando a natureza contradiz as condições nas quais é possível para nós levar adiante nossa existência" (IBID) com o impulso de autoconservação no domínio prático.

A razão, por sua vez, se opõe à dependência da natureza se apresentando como domínio da independência, manifesta por duas formas: "em primeiro lugar, na medida em que podemos ultrapassar as condições naturais (no que é teórico) e pensar mais do que conhecemos;" (IBID), isto é, superamos o domínio da dependência no que diz respeito ao impulso de representação quando podemos pensar além do que nos é permitido, ou "em segundo lugar, na medida em que podemos passar por cima das condições naturais (no que é prático) e contradizer nosso apetite através da vontade" (IBID), isto é, por meio da vontade podemos garantir nossa liberdade 
diante das inclinações e condições impostas naturalmente. Segundo Pedro Süssekind, "essa explicação remete à questão antropológica formulada por Kant, especialmente no domínio de sua filosofia prática, ou seja, à noção de que o homem é um cidadão de dois mundos" (IBID., p. 89), determinado naturalmente por dois impulsos, "[...] o de tentar entender o mundo e o de se esforçar para preservar sua existência." (IBID).

Embora Schiller se lance a partir de um problema proposto por Kant, seu intuito vai além da descrição das noções e problemas do filósofo que o influiu. Segundo Ricardo Barbosa, Schiller, além de escritor e dramaturgo, foi também "dotado para a reflexão filosófica [...]" (BARBOSA, 2011, p. 204), por isso, o "[...] problema prático da criação artística, e sobretudo o da criação literária, jamais foi tratado por ele como um problema estritamente técnico [...]" (IBID). Problemas filosóficos também não são tratados apenas enquanto tais. Em suas multifacetadas habilidades, Schiller foi capaz de transformar ambos os domínios em “[...] um autentico problema estético" (IBID). Por conta disso, pode-se notar o ímpeto em querer ir além do problema kantiano: Schiller pretende entender os conflitos humanos à base da filosofia e apresentá-los por meio da arte trágica, de modo a compreender toda a fatalidade da existência nela mesma, abordando então noções que estão enraizadas na natureza mais genuína do homem: seus impulsos. De acordo com Vladimir Vieira:

Como nos demais artigos que escreveu nesse período, Schiller procura introduzir nuances e qualificar melhor certos aspectos da doutrina kantiana. Ao descrever o conflito que está na base do sentimento do sublime, por exemplo, ele recorre às noções de impulso de representação e autoconservação para caracterizar a parte sensível, respectivamente, nos casos matemático e dinâmico [...]. (VIEIRA, 2011, p. 13).

Sob as noções de impulsos e a dupla relação de dependência e independência para com a natureza, Schiller adotou para os sublimes matemático e dinâmico de Kant uma nova nomenclatura: ele os chamou, respectivamente, de sublime teórico e sublime prático. O motivo dessa mudança se dá, pois, “[...] dos conceitos dinâmico e matemático não se pode concluir se a esfera do sublime está ou não esgotada por essa divisão [...]" (IBID., p. 24). Schiller toma tal posicionamento, pois, como nos atesta Ricardo Barbosa:

Quanto à dúvida sobre se a divisão estabelecida por Kant esgota a esfera do sublime, é de se supor que Schiller estivesse convencido de que a distinção entre o teórico e o prático fosse mais coerente sob o aspecto arquitetônico da crítica da razão e mais adequada aos seus próprios fins como autor dramático, pois, sob este aspecto, seu principal interesse era investigar a fundo a natureza do trágico, [...]. (BARBOSA, 2014, p. 91-92).

No caso do sublime teórico, o desprazer se funda na ameaça causada pela natureza ao percebermos que ela detém as condições responsáveis por permitir que façamos nossas representações sensíveis, isto é, ela detém nosso conhecimento. Dessa maneira, quando em perigo, nosso impulso de representação se torna responsável por salvaguardar tal faculdade. Este sublime representa a infinitude e se caracteriza por sentirmos subjugados intelectualmente a algo maior que nós, característica que nos faz sentir toda a dependência que a natureza nos impõe, uma vez que é ela que nos oferece as condições para tal.

No entanto, quando nos sentimos ameaçados e somos impelidos a entrar em ação para que não sucumbamos, nosso impulso de representação ou conhecimento nos mostra que, apesar da natureza ser capaz de nos limitar, nosso pensamento pode ir além do que lhe é dado. Assim, Schiller o descreve: “Um objeto é sublime de modo teórico na medida em que traz consigo a representação da infinitude, para cuja apresentação a faculdade da imaginação não se sente à altura." (SCHILLER, 2011, p. 25).

Em Kant o sublime matemático é algo "absolutamente grande" (KANT, 1993, p. 93). Embora seja caracterizado desse modo, o autor da terceira Crítica adverte que não se pode pensar nesta grandeza enquanto uma propriedade física, dado que, se assim fosse, 
seria necessário pensá-la sempre em relação a algo. Isto tornaria o objeto responsável por desencadear este sublime algo empírico e relativo. Segundo Kant, o sublime deve se estabelecer por "[...] um padrão de medida que se pressupõe poder admitir como o mesmo para qualquer um [...]" (IBID., p. 94), sendo "[...] somente estético da grandeza, porque ele é um padrão de medida que se encontra subjetivamente à base do juízo reflexivo sobre grandeza." (IBID). Assim, seu tamanho é distinto de qualquer objeto sensível, pois é considerado absolutamente grande pela incapacidade de compará-lo aos outros. Por conta disso, ele pode ser reconhecido independente de quaisquer comparações como algo grandioso. Essa característica do objeto sublime de modo matemático torna improvável sua existência na natureza, visto que sua propriedade não é física, mas sim estética. Nas palavras do autor:

Se, porém, denominamos algo não somente grande, mas simplesmente, absolutamente em todos os sentidos grande, isto é, sublime, então se tem a imediata perspiciência de que não permitimos procurar para o mesmo nenhum padrão de medida adequado a ele fora dele, mas simplesmente nele. Trata-se de uma grandeza que é igual simplesmente a si mesma. Disso segue-se, portanto, que o sublime não deve ser procurado nas coisas da natureza, mas unicamente em nossas ideias. (IBID., p. 96).

Quanto à relação entre as faculdades, podem-se notar dois aspectos fundamentais no sublime matemático: o insucesso da imaginação e, por conseguinte, a percepção da potência da razão - característica que se encontra na base da descrição do sentimento do sublime. Esta relação entre a faculdade da imaginação e da razão torna possível o ajuizamento do sublime matemático. Nele, a imaginação que se encarrega de apresentar a sensação grandiosa falha, dado que sua grandeza não pode se adequar a qualquer representação que se faça num plano empírico.

Por outro lado, a razão pretende abarcar "a totalidade absoluta como a ideia real, mesmo aquela inadequação a esta ideia de nossa faculdade de avaliação da grandeza das coisas do mundo dos sentidos desperta o sentimento de uma faculdade suprassensível em nós" (IBID., p. 96). Isto é, pelo fracasso da imaginação, a razão passa a pensar a grandeza absoluta do sublime em sua totalidade. Neste momento, o sujeito vislumbra sua infinitude, isto graças à "faculdade do ânimo que ultrapassa todo padrão de medida dos sentidos." (IBID., p. 96). Assim, a limitação da faculdade da imaginação em compreender o absolutamente grandioso consiste no desprazer do sublime, entretanto, este mesmo sentimento de limitação faz com o sublime se torne prazeroso.

O sublime prático, por sua vez, se revela quando a natureza torna conflituosa a condição de nossa existência. Nas palavras de Schiller, "Um objeto é sublime de modo prático na medida em que traz consigo a representação de um perigo que nossa força física não se sente capaz de vencer." (SCHILLER, 2011, p. 25). Desse modo, no sublime prático sucumbimos quando tentamos opor nossa força física a algo que é indubitavelmente mais forte e poderoso que nós e que, além disso, pode nos arrasar por completo. Assim, segundo Schiller:

O sublime prático se diferencia, assim, do sublime teórico pelo fato de que o primeiro está em conflito com as condições de nossa existência, ao passo que o último apenas com as condições do conhecimento. [...]. Sucumbimos na tentativa de realizar uma representação do primeiro; e sucumbimos na tentativa de nos contrapor ao poder do segundo. (SCHILLER, 2011, p. 25)

Em Kant, O sublime dinâmico se caracteriza pelo seu poder e força. Com isto, esta sensação nos é desencadeada sob a pretensa de algo que nos causa temor ou que nos seja terrível. Kant se refere principalmente à natureza quando fala deste sublime, dado que ela é nosso maior símbolo de fragilidade, pois, enquanto seres naturais somos frágeis perante suas forças causais. No entanto, esta violência exercida só é sublime quando a natureza sobrepõe a nós sua força mostrando-nos nossa própria 
fragilidade e inferioridade perante ela - característica fundamental deste sublime. Força que, no entanto, não nos fará sucumbir, dado que detemos uma faculdade pela qual nos distinguimos dela, a saber, a razão.

Assim, nas palavras de Kant, "a natureza, considerada no juízo estético como poder que não possui nenhuma força sobre nós, é dinamicamente-sublime" (KANT, 1993, p. 106). Neste sentido, o nosso desprazer advém dessa força opressiva que, quando superada pela razão passa a nos atrair, criando então uma disponibilidade em nosso ânimo pela percepção de que podemos superar tal poder capaz de nos ameaçar. Este interesse pelo ajuizamento do sublime da natureza tem, segundo Kant, "seu fundamento na natureza humana" (IBID., p. 112), se dispondo impreterivelmente a qualquer sujeito.

Tudo o que suscita este sentimento em nós, a que pertence o poder da natureza que desafia nossas forças, chama-se então (conquanto impropriamente) sublime; e somente sob a pressuposição desta ideia em nós e em referência a ela somos capazes de chegar à ideia da sublimidade daquele ente, que provoca respeito interno [...] através da faculdade, que se situa em nós, de ajuizar sem medo esse poder e pensar nossa destinação como sublime para além dele. (IBID., p.110).

Em consonância a Kant, Schiller utiliza-se do mesmo exemplo para explicar a distinção entre ambos os sublimes: "Um exemplo do primeiro [sublime teórico ou matemático] é o oceano em calmaria [...]" (SCHILLER, 2011, p. 25), como representante da capacidade da natureza fora de nós que, como um oceano em calmaria, não exerce veementemente poder capaz de exterminar nossa existência, mas se mostra, assim como o conhecimento, como algo vasto e grandioso. Como exemplo do sublime prático ou dinâmico, ambos os autores se utilizam do "[...] oceano em tempestade [...]" (IBID), o qual tem como propriedade a vastidão e pode representar um perigo efetivo.

Após definidos os objetos de cada sublime, Schiller define a intensidade como cada qual opera em nossa sensibilidade, característica que define também o interesse despertado por eles. Segundo o autor, o sublime teórico diz respeito aos objetos versados como infinitos e grandiosos, diante dos quais qualquer ser humano sentiria sua pequenez e a limitação de sua faculdade da imaginação na tentativa de apreendê-los. O sublime prático, por sua vez, diz respeito a objetos que suscitam o temor e o sofrimento, os quais excedem a resistência sensível humana por sua força implacável. Essas particularidades fundam a distinção necessária entre o sensível e o suprassensível capaz de ser conscientemente percebida.

A consciência da distinção entre estas duas esferas do âmago humano é fundamental para que a sensação tida diante de tais objetos seja propriamente sublime. Sem essa consciência de que enquanto seres sensíveis sucumbiríamos, mas que enquanto seres racionais podemos ir além do que nos é consumado empiricamente, não haveria sublime, dado que, para Schiller, "[...] toda a essência do sublime está baseada na consciência dessa nossa liberdade racional, e que todo prazer no sublime está fundado, justamente, apenas em tal consciência, [...]" (IBID., p. 27).

De acordo com o que afirma Pedro Süssekind, isso se dá por conta da forma como o desprazer de cada sublime se relaciona com nossas faculdades: no sublime teórico é suscitado, nas palavras de Süssekind, "[...] apenas a capacidade cognitiva de intuir a forma de um objeto; [...]" (IBID., p. 90), enquanto a experiência do sublime prático suscita nosso "[...] impulso de autoconservação, inclinação determinante da existência do homem enquanto ser natural" (IBID). Embora o desprazer se faça presente também no sublime teórico por contrariar o papel ativo da faculdade da imaginação na tentativa de apreender o objeto sublime em sua vastidão, no sublime prático há o sofrimento efetivo. Por isso, sua intensidade é mais vivaz, uma vez que ameaça não apenas um fundamento de nossa existência, mas ela como um todo. 
Desse modo, Schiller atribui maior importância ao sublime prático em suas considerações acerca do sublime: é nele que se dá a relação mais intrínseca com a nossa existência. Diante de tal sublime, o impulso de autoconservação é impelido a conservar não apenas um aspecto de nossa existência, mas ela toda. Por essa razão, o sofrimento e temor podem ser sentidos de modo mais intenso e vivaz que a representação do infinito.

A partir dessa distinção a respeito do grau de intensidade, Schiller ansiou contribuir com a teoria do sublime e seu debate na modernidade, pois, o filósofo estaria, sob as considerações de Pedro Süssekind, "[...] a fim de solucionar um problema que ele identifica nas teorias de seus precursores, incluindo na kantiana. Como contribuição para o percurso histórico da teoria do sublime na modernidade." (IBID., p. 91). A qual pode ser pensada em dois âmbitos distintos da teoria do sublime: primeiro, "[...] como exploração de uma experiência estética mais intensa do sublime, para além de sua restrição à segurança do observador;" (IBID), em que é fundamental certo distanciamento, capaz de tornar o desprazer próprio ao sublime em algo prazeroso, uma vez que, diante de um sofrimento efetivo, o sujeito padeceria. E a segunda: "[...] como transposição do sublime a natureza para o sublime na arte." (IBID).

O intuito de Schiller é, pois, tornar possível o prazer sublime mesmo diante das experiências de sofrimento e temor, isto é, de modo objetivo e direto. Schiller não deixa de concordar com Kant, dado que, para ambos, no momento em que o desprazer se torna efetivo a imaginação perde a liberdade que permite a ela entrar e um jogo livre entre as faculdades - característico ao ajuizamento estético - para nos direcionar ao impulso de autoconservação. Schiller sabe das consequências que o sofrimento propriamente efetivo e verdadeiro pode causar ao sujeito que o sofre. No entanto, o filósofo pensa a possibilidade de objetivá-lo, porém, de modo solidário, isto é, por meio do reconhecimento em outro homem, aquele que se dispõe a acompanhá-lo sentiria seu sofrimento por um sentimento de compaixão.

Contudo, Schiller procura como solução para a segurança necessária um fundamento que, segundo ele, "[...] não está à mão nenhum fundamento físico para a tranquilização" (IBID), isto é, ele pretende uma elevação sublime que assegure efetivamente que, mesmo "[...] quando pensamos no destino em toda a sua temibilidade, temos de nos dizer prontamente que não estamos de modo algum 'subtraídos' a ele" (IBID). Seu interesse não está, pois, somente em uma teoria da Tragédia ou na explicação do ajuizamento estético do sublime; Schiller quer levar às últimas consequências a teoria do sublime de modo a fazer uma teoria do próprio trágico, onde seu fundamento possa ser aplicado à própria existência. Neste sentido, ele não pretende fazer com que o homem deixe de sofrer diante de uma representação temível; ele quer, sobretudo, que todo homem ascenda ao sublime em sua própria existência trágica.

Há, segundo Schiller, um duplo fundamento pelo qual essa segurança se estabelece: segurança física; nos casos em que conseguimos nos salvaguardar por meio de nossa faculdade física. Em casos de "males aos quais não estamos em condição de resistir ou dos quais não podemos nos esquivar por um caminho natural, podemos ter apenas segurança interna moral" (IBID., p. 34). Segundo o autor, a segurança física tranquiliza a nossa sensibilidade: é ela quem impede que o impulso de autoconservação seja intimidado. No entanto, apenas tranquiliza nossa sensibilidade e impede que a razão suspenda nossa liberdade de ânimo.

Todavia, essa tranquilidade se funda no fato de sabermos que racionalmente somos ameaçados, isto é: "Olhamos o temível sem temor porque nos sentimos, enquanto seres naturais, subtraídos a seu poder sobre nós, seja pela consciência de nossa inocência, seja pelo pensamento da indestrutibilidade de nosso ser." (IBID). Essa distinção é fundamental para se compreender em que se funda o sublime. Em suas palavras: 
O objeto do sublime prático tem de ser temível para a sensibilidade; um mal tem de ameaçar o nosso estado físico, e a representação do perigo tem de colocar em movimento o impulso de autoconservação. Nosso eu inteligível, aquilo em nós que não é natureza tem de se diferenciar da parte sensível de nosso ser em cada afecção do impulso de conservação e se tornar consciente de sua autonomia, de sua independência de tudo aquilo que a natureza física pode atingir - em suma, de sua liberdade. Essa liberdade é, entretanto, absolutamente moral, e não física. (IBID., p. 38).

Essas características do sublime prático levam Schiller a estabelecer três aspectos sobre os quais este sublime deve compor em sua representação, que são: "I. a representação de um poder físico objetivo; II. a representação de nossa impotência física subjetiva; III. a representação de nossa supremacia moral subjetiva." (IBID., p. 40). Assim, o autor fez em Do sublime uma classificação do sublime prático em sublime contemplativo do poder e sublime patético. Embora ambos os sublimes devam ter as características citadas acima em comum, é distinto o modo como podem ser representados, e nisso se funda a razão da classificação schilleriana desses sublimes.

\section{Conclusão}

Através da leitura de Do sublime, podemos notar que Schiller pretendia se utilizar da filosofia kantiana para, a partir dela, pensar o sublime e sua fruição estética. Todavia, não se pode deixar de notar a autonomia do filósofo na construção da teoria do sublime. Por isso, fez-se necessário pontuar neste mesmo ensaio as contribuições do próprio filósofo, especialmente nos momentos em que resolve renomear os sublimes matemático e dinâmico de Kant, como sublime teórico e sublime prático, e também sua nova subdivisão de sublime prático em contemplativo do poder e patético, tomando o último como próprio à tragédia.

Com isso, Schiller pensou a arte trágica como o melhor meio de se alcançar o sublime e, assim, realizou, nas palavras de Pedro Süssekind, "[...] uma transposição do sublime da natureza, como foi pensado pelos teóricos do século XVIII, para a arte" (IBID., p. 94), uma vez que deixa de adotar a natureza como único meio para a sensação sublime.

Assim, a arte trágica em Schiller tem em seu fundamento a representação objetiva do sofrimento por meio do sentimento solidário, que torna seu sublime tão vivaz e intenso quanto à representação da natureza, porém, de modo estético.

***

Correspondência: Bárbara Ferrario Lulli. Universidade Estadual Paulista Júlio de Mesquita Filho - UNESP. Faculdade de Filosofia e Ciências - FFC. Av. Higino Muzi Filho, 737. Bairro Mirante. Marília - SP - Brasil. CEP: 17525-900. E-mail: barbaraflulli@gmail.com

Apoio financeiro: FAPESP.

Conflito de interesses: Nenhum

Todos os autores leram e aprovam a versão final submetida à revista Em curso. 


\section{Bibliografia}

BARBOSA, R. As três naturezas: Schiller e a criação artística. In: Magrata. Rio de Janeiro. v.18 n. 29. p. 201-214. jul/dez. 2011.

Schiller e a cultura estética. Rio de Janeiro: Ed. Zahar. 2004.

. Sobre o sublime teórico em Schiller e o espírito trágico do idealismo transcendental. In: Analytica. Rio de Janeiro. vol.18 n.2. p. 85-108. 2014.

KANT, I. Crítica da faculdade do juízo. Tradução de Valério Rohden e António Marques. 2. ed. Rio de Janeiro: Forense, 1993.

Fundamentação da metafísica dos costumes. Tradução de Paulo Quintela. Lisboa/Portugal: Edições 70 Ltda. 2007.

LYOTARD, J. F. Lições sobre a analítica do sublime. Tradução de Constança Marcondes Cesari e Lucy R. Moreira Cesar. Campinas/SP: Papirus. 1991

ROBERTSON, R. “On the sublime” and Schiller's theory of tragedy. In: Philosophical Readings. vol. 05. p. 194-212. 2013. Disponível em: https: / / philosophicalreadings.files.wordpress.com/2014/10/pr2013. pdf. Acesso em: 14 maio. 2016.

ROSENFELD, A. Teatro alemão: História e estudos. Parte I. 2. ed. São Paulo: Ed. Brasiliense. 1968.

SCHILLER, F. A Educação estética do homem: Numa série de cartas. Tradução de Roberto Schwarz e Márcio Suzuki. 2. ed. São Paulo: Iluminuras. 1990.

Autêntica, 2011.

Do sublime ao trágico. Tradução de Pedro Süssekind e Vladimir Vieira. São Paulo:

Kallias ou sobre a beleza: A correspondência entre Schiller e Körner, janeiro-fevereiro 1793. Tradução de Ricardo Barbosa. Rio de Janeiro: Jorge Zahar Ed. 2002

Teoria da tragédia. Tradução de Anatol Rosenfeld. 2. ed. São Paulo: E.P.U., 1991.

SÜSSEKIND, P. O impulso lúdico: Sobre a questão antropológica em Schiller. In: Artefilosofia. Ouro Preto. n.10. p.11-24. Abr. 2011.

VIEIRA, V. Entra a razão e a sensibilidade. A estética pós-kantiana e o problema da cisão entre sensível e suprassensível. 2009. 232 f. Tese (Doutorado em Filosofia). Instituto de Filosofia e Ciências Humanas, Universidade Federal do Rio de Janeiro.

O duplo papel da imaginação no sublime kantiano. In: Artefilosofia. Ouro Preto. n.14. p. 105-111. julho 2013

Recebido em: 26/Mar/2017 - Aceito em: 29/Nov/2017. 